\title{
Guest-editor's Preface
}

\section{Chaos and Self-Organization in Companies}

\section{Arno L. GOUDSMIT}

University of Groningen, Dept. of Psychology, and

The Giambattista Vico Institute, Amsterdam, Netherlands

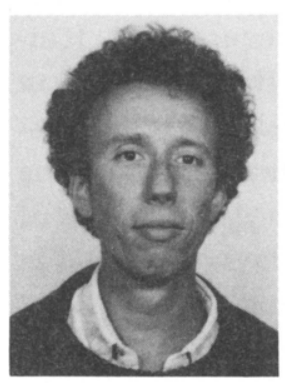

Arno L. Goudsmit (1955) studied psychology and philosophy. He teaches foundations of psychology at the University of Groningen. He has published on various topics in non-classical cybernetics and constructivism.

IOS Press

Human Systems Management 9 (1990) 203-204
This issue of HSM presents the papers that were presented at a recent symposium, organized by the University of Groningen in collaboration with NIVE (the Management Association of the Netherlands) and the Giambattista Vico Institute in Amsterdam.

The basic phenomenon that is underlying the various presentations of this symposium, as well as the various theoretical and practical developments of which they are an expression, is the interplay between stable and instable stages in the behavior of complex systems. But what is stable? Whether something is perceived as stable or not is dependent from the capacities of those who are looking for regularities and patterns. Stability and instability are intimately linked with perceptual properties of the observer. Modern managers' problems in meeting the overwhelming amounts of information that their jobs entail, are to a large extent of a perceptual nature.

But, unlike more traditional approaches to perception and information, the kind of thinking that is concerned with issues of self-organization and chaos does not attempt to disentangle the properties of the perceiver from those of the perceived phenomena. For it is precisely here, at this interface between perceiver and perceived, that the phenomena of self-organization emerge and show their unpredictable courses of development. And it is this very interface that is usually beyond the attention of those involved. It is at this interface also that efforts to perceive what happens at this very interface, have their most interfering and obtrusive effects.

For management this has several implications.

First, the system managed coincides for a large degree with the way in which it is managed. It is essentially impossible to separate the two. Any at- 
tempts to do so (like in most of the classical models) ignores the merge between subject and object, manager and managed.

Second, the system managed cannot be denied the perceptual qualities of the variety the manager might be inclined to preserve for himself and his staff. Those organizational behaviors which the manager finds so hard to categorize and to predict are basically of a perceptual nature, and, for that reason, these behaviors receive their shape only at the interface with those issues that are perceived. This is the issue of 'local intelligence' and 'adequate action': modes of operation that do not execute particular predefined procedures.

Third, that which happens in an organization can always be dealt with from two points of view: either from the outside, or from the inside. An external point of view will lead to perceptions and understandings of the organization in terms control and regulation. These are the gains of the classical approaches. On the other hand, an internal point of view will lead to the merge of precisely two points of view: the external and the internal point of view. Indeed, this is a paradoxical formulation: the inside of a self-organizing system exists as a merge of its own inside with its own outside, whereas its outside is qualified by a clear distinction between inside and outside! Stepping into the system's inside requires a suspense of one's need for a clear logical bookkeeping; what is steering and what is steered become of the same logical type. Stepping out of the system restores this bookkeeping, but diminishes the immediate contact with the system. It is precisely this asymmetrical relation between inside and outside which makes the idea of self-organization not 'just a new toy' for those interested in organizational processes.

The papers in this issue present a variety of views upon this theme. Rob Zuijderhoudt's 'perspective levels for changes' for example show the various positions a manager (and a consultant) can take in relation to the system's self-organizing processes. Diana Watts discusses some ways to drop the predefined and rigid structures of organizations. Tineke Bahlmann presents some ideas concerning third order learning in organizations, and René Feyen gives some metaphors on boundaries and order in organizations.

Finally, let me make a few remarks about the paper by Philip Boxer and Vincent Kenny that is given a first place in this issue. I found this paper very difficult, but also daring and courageous. It attempts to lay out an agenda for the establishment of a third-order cybernetics. It seeks to do this first by exploring some of the problematics of working with systemic approaches under the general aegis of second-order cybernetics. It then lays out what is in effect an overview and introduction to Lacan's approach to the subject. Finally it offers two cases which lead the reader into a consideration of the ethics of consultancy. This is in a way too much to try to hold together within this form of paper. It demands a lot of the reader, both in terms of patience and the range of background knowledge expected. As it stands, it calls into question the reader's position at least as much as the writers'. This I find an interesting effect in a paper about a third order! I hope therefore that the reader will enjoy it as much for the challenge it presents as for the coherence of its presentation. 